\title{
Development and Evaluation of Mucoadhesive Tablets of Cinnarizine Using Carboxymethylated Guar Gum by Compression Coating Technique
}

\author{
Pankaj Giri ${ }^{1} \mathbb{D}$, Inderbir Singh $1, * \mathbb{D}$ \\ 1 Chitkara College of Pharmacy, Chitkara University, Punjab, India \\ * Correspondence: inderbir.singh@ @hitkara.edu.in (I.S.);
}

Scopus Author ID 7401774846

Received: 15.04.2020; Revised: 7.05.2020; Accepted: 8.05.2020; Published: 13.05.2020

\begin{abstract}
The e study was designed to perform carboxymethylation of guar gum and to develop mucoadhesive tablets of cinnarizine by compression coating technology. Carboxymethyl guar gum was synthesized and characterized by FTIR, SEM, XRD and DSC techniques. Inner core tablets of cinnarizine were compression coated with guar gum and carboxymethylated guar gum. The formulated mucoadhesive tablets were evaluated for various tablet parametric tests viz. hardness, friability, content uniformity, thickness. Ex vivo mucoadhesion strength and in vitro drug release studies were also conducted. Appearance of new FTIR peaks, surface morphology analysis by SEM, reduction in crystallinity by XRD and appearance of the endothermic peak in DSC thermogram point out towards successful carboxymethylation of guar gum. Mucoadhesive strength of F1CGG to F4CGG batches of mucoadhesive tablets prepared with carboxymethyl guar gum found higher than F1GG to F4GG batches of tablets prepared with guar gum. Carboxymethyl guar gum exhibited sustained release effect on in vitro release cinnarizine from compression coated mucoadhesive tablets.

The study confirms that carboxymethylation of guar gum improves the mucoadhesive properties of pure guar gum. Also, the compression coating of carboxymethylated guar gum enhances the gastric retention time and sustained release of cinnarizine. Carboxymethyl guar gum can be used as mucoadhesive polymer for developing different mucoadhesive drug delivery systems.
\end{abstract}

Keywords: Carboxymethylation; Guar gum; Compression coating; Mucoadhesive tablets; Cinnarizine.

(C) 2020 by the authors. This article is an open access article distributed under the terms and conditions of the Creative Commons Attribution (CC BY) license (https://creativecommons.org/licenses/by/4.0/).

\section{Introduction}

Mucoadhesive drug delivery systems offer several advantages including increased residence time of drug at the site of application, increased permeability of drug into the systemic circulation and enhanced bioavailability of the drug. Mucoadhesion phenomenon could be illustrated in three steps: first step involves wetting and swelling of the polymer; second, interpenetration and/or entanglement of the polymer and the mucin chains; and finally, the formation of bond leading to adhesion of the polymer to the mucosal surface. Mucoadhesive drug delivery systems could be designed for potentially targeting ocular, oral, buccal, nasal, vaginal and rectal routes for administration of drugs [1,2].

Cinnarizine is an antihistaminic drug used for the control of nausea and vomiting due to motion sickness. It exhibits $\mathrm{pH}$-dependent dissolution behavior and dissolves readily at $\mathrm{pH}$ $1(1.5 \mathrm{mg} / \mathrm{ml})$, and has a very low solubility at $\mathrm{pH}$ values greater than 4 . Cinnarizine, being a 
weakly basic drug, precipitates in the basic $\mathrm{pH}$ of the small intestine. Incorporation of cinnarizine into mucoadhesive drug delivery system retains the drug in the stomach environment for a longer duration. This could enhance the bioavailability of cinnarizine [3]. Singh and Rana developed mucoadhesive tablets of cinnarizine using Eudragit RLPO and iron oxide [4].

Guar gum is a biopolymer obtained from the seeds of Cyamopsis tetragonolobus of family Leguminosae. It is mainly composed of high molecular weight polysaccharides in which $(1 \rightarrow 4) \beta$-D mannopyranosyl units are linked with $(1 \rightarrow 6) \alpha$-D galactopyranosyl residues. It has a strong hydrogen bond forming capability in water which makes it a useful stabilizer and thickner. Due to its thickening, gelling, emulsifying, $\mathrm{pH}$ stability, binding and film forming properties, it is widely used in pharmaceutical, food, textile, paper, oil, cosmetic and paint industries [5,6]. Carboxymethylation of guar gum was successfully performed and was used for developing matrix tablets of metronidazole $[7,8]$.

Compression coating is a solvent free coating technique in which the inner core is coated with the outer layer by compression. Materials used in the outer layer could be employed for modifying mechanical strength, altering drug release pattern and enhancing drug stability. Mucoadhesive and gastro-floating tablets have already been developed by compression coating employing conventional polymeric materials $[9,10]$.

In the present research, carboxymethylation of guar gum was performed and FTIR, SEM, XRD, DSC techniques were employed for the characterization of the modified gum. Core tablets of cinnarizine were prepared which were compression coated with pure guar gum and carboxymethylated guar gum. The formulated compression coated tablets were evaluated for various tablet parametric tests. Ex vivo mucoadhesion and in vitro drug release studies were also performed.

\section{Materials and Methods}

\subsection{Materials.}

Cinnarizine was received as a gift from Ind-Swift Pharmaceutical, India. Guar gum was kindly supplied as a gift sample by Hydrocolloid Plantations, New Delhi, India. MCC (Avicel112), sodium hydroxide, monochloro-acetic acid, methanol, glacial acetic acid, PVP K30, talc, magnesium stearate were procured from Loba Chemie, Mumbai, India. All chemicals and reagents employed in the study were of analytical grade.

\subsection{Carboxymethylation of guar gum.}

Carboxymethylation reaction of guar gum was performed by modifying the method described by Gong et al. [11]. Purified gum (10 g) was dissolved in $500 \mathrm{ml}$ of distilled water followed by dropwise addition of sodium hydroxide over s period of 30 minutes with continuous stirring. Monochloro acetic acid was added slowly to the above mixture. The temperature of the reaction mixture was raised to $50{ }^{\circ} \mathrm{C}$ and stirred for $4 \mathrm{hrs}$. Methanol $(85 \%)$ was added to the mixture for precipitating the carboxymethylated gum. The modified gum was washed, dried and stored in desiccator. Reaction for the synthesis of carboxymethyl guar gum is depicted in Figure 1. 

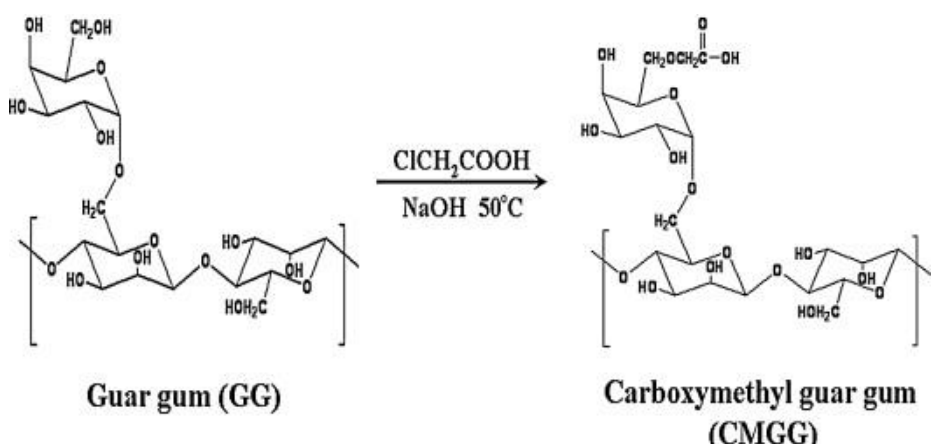

Figure 1. Synthesis reaction for the modification of guar gum into carboxymethylated guar gum.

\subsection{Characterization of carboxymethyl guar gum}

The carboxymethyl guar gum was characterized by FTIR spectroscopy, SEM, XRD, and DSC techniques.

\subsubsection{Fourier transform infrared spectroscopy.}

The Fourier transform infrared (FTIR) spectra of sampleswere obtained using attenuated total reflectance (ATR)-FTIR spectrophotometer (Alpha, Bruker, Japan). The samples of pure gum and carboxymethylated gum werescanned in the spectral region of 4000 $\mathrm{cm}^{-1}$ to $400 \mathrm{~cm}^{-1}$.

\subsubsection{Scanning electron microscopy.}

Scanning electron microscopy (SEM) photomicrographs weretaken for studying surface morphology of pure gum and carboxymethylated gum by scanning electron microscope (Hitachi S $4300 \mathrm{SE} / \mathrm{N}$ ) equipped with a secondary electron at an accelerating voltage of $10 \mathrm{kV}$. Samples were mounted directly ontothe SEM sample stub using double-sided sticking carbon tape under reduced pressure $(0.001 \mathrm{~mm} \mathrm{Hg})$.

\subsubsection{X-ray diffraction analysis.}

Samples of pure gum and carboxymethylated gum were mounted in the sample cell and scanned between $2 \theta$ of $0-60^{\circ}$ with a counting time of 0.1 seconds step size. X-ray patterns of the films were obtained with XPERT-PRO equipment (PANalytical, Netherland).

\subsubsection{Differential scanning calorimetry.}

Samples of pure gum and carboxymethylated gum were sealed hermetically in flat bottom aluminum cells and were subjected todifferential scanning calorimetry (DSC) analysis (MettlerToledo Star System, 305, Switzerland) at a heating rate of $10^{\circ} \mathrm{C} / \mathrm{min}$ under nitrogen atmosphere.

\subsection{Preparation of core tablets of cinnarizine.}

Core tablets were prepared as per the formula given inTable 1. All the ingredients were passed through 60\# sieve,followed by mixing for 15 minutes by tumbling. Tablets with atheoretical weight of $80 \mathrm{mg}$ were obtained using multipunchtableting machine (A $\mathrm{K}$ Industries, Nakodar, India) fitted with6-mm concave round die-punch tooling [12]. 
Table 1. Composition of core tablet of cinnarizine.

\begin{tabular}{l|l} 
Constituents & Quantity $(\mathbf{m g})$ \\
\hline Cinnarizine & 15 \\
\hline Avicel-112 & 58 \\
\hline PVP K-30 & 5 \\
\hline Talc & 1 \\
\hline Magnesium Stearate & 1 \\
\hline Total weight & 80
\end{tabular}

\subsection{Compression coating of core tablets.}

The formulated core tablets were press coated with anappropriate blend of coating polymer as shown in Table 2. Avicel-112 was added quantity sufficient for making the total tablet weight equal to $600 \mathrm{mg}$. Half the quantityof the coating polymer was filled into the die cavity ( 8.5 mmdiameter). The core tablet was placed in the centre of the diecavity, which was then filled with the remainder of the coatingmaterial. Then, it was compressed around the core tablets at an applied force of $5000 \mathrm{~kg}$ using $8.5 \mathrm{~mm}$ concave punchesfitted to multipunch tableting machine [13].

Table 2. Compression coating composition for mucoadhesive tablet batches of pure guar gum and

\begin{tabular}{l|c|c|c|c} 
Batches & $\begin{array}{c}\text { Guar Gum } \\
(\mathbf{m g})\end{array}$ & $\begin{array}{c}\text { Carboxymethylated Guar Gum } \\
(\mathbf{m g})\end{array}$ & $\begin{array}{c}\text { PVP K30 } \\
(\mathbf{m g})\end{array}$ & $\begin{array}{c}\text { Talc } \\
(\mathbf{m g})\end{array}$ \\
\hline F1GG & 350 & - & 20 & 5 \\
\hline F2GG & 400 & - & 20 & 5 \\
\hline F3GG & 450 & - & 20 & 5 \\
\hline F4GG & 500 & - & 20 & 5 \\
\hline F1CGG & - & 350 & 20 & 5 \\
\hline F2CGG & - & 400 & 20 & 5 \\
\hline F3CGG & - & 450 & 20 & 5 \\
\hline F4CGG & - & 500 & 20 & 5
\end{tabular}

\subsection{Evaluation of core and compression coated tablets.}

To ensure the uniformity and mechanical integrity of the prepared tablets, the following parameters like weight variation, hardness, friability, and drug content were measured using the parameters calculated as per standard parameters.

\subsubsection{Hardness and friability.}

Hardness and friability were determined using the validated Monsanto hardness tester and the Roche friabilator (Campbell Electronics, Mumbai, India), respectively.

\subsubsection{Thickness.}

The thickness of the tablets was determined using Digital Vernier Caliper (Mitutoyo Absolute Digimatic Caliper, Japan). Five tablets from each formulation were used and the average values were calculated.

\subsubsection{Drug content.}

Five tablets were weighed individually and powdered. The powder equivalent to the average weight of tablets was weighed and drug was extracted in $0.1 \mathrm{~N} \mathrm{HCL}$, the drug content 
was determined to measure the absorbance at $254 \mathrm{~nm}$ after suitable dilution using UV-Vis double beam spectrophotometer (AU 2701, Systronics, Mumbai, India).

\subsubsection{Ex vivo determination of mucoadhesive strength.}

Mucoadhesion testing of the prepared compression coated tablets was performed using texture analyzer (TA.XT plus, Stable MicroSystems, UK). Sample tablet was fixed to the cylindrical probe with the help of double side adhesive tape. The pig stomach tissue (about $20 \times 20 \mathrm{~mm}$ ) was equilibrated for $15 \mathrm{~min}$ at $37.0 \pm 0.5^{\circ} \mathrm{C}$ before placing onto the holder stage. The probe with the sample tablet attached was immersed in the test medium for a specified time prior to the test, the hydrated disc was then moved downward to contact with soaked tissue at a specified force and maintained until a specified time. The probe was withdrawn at a specified test speed and the maximum detachment force (Fmax) required to separate the sample tablet fitted probe from the tissue could be obtained directly from Texture Exponent 32 software. The preliminary settings of the instrument were: test speed $0.5 \mathrm{~mm} / \mathrm{s}$, contact force $1.0 \mathrm{~N}$, contact time $60 \mathrm{~s}$ and return distance $15 \mathrm{~mm}$. The probe without a sample tablet was also tested to check the uniformity of the animal tissue [14].

\subsubsection{Invitro drug release.}

The in vitro dissolution study on compression coated mucoadhesive tablets of cinnarizine was carried out in a paddle-type six station dissolution apparatus (DS 8000, LabIndia, India) with a stirring speed of $50 \mathrm{rpm}$ at $37 \pm 0.5 \mathrm{C}$ using $900 \mathrm{ml}$ of $0.1 \mathrm{~N} \mathrm{HCl}(\mathrm{pH}$ 1.2) as dissolution medium. At predetermined time intervals, $5 \mathrm{ml}$ samples were withdrawn, filtered through a $0.45 \mu \mathrm{m}$ membrane filter, diluted and analyzed at $254 \mathrm{~nm}$ using a UV/VIS double beam spectrophotometer (2202, Systronics, India).Cumulative percentage of drug release was calculated using an equation obtained from the calibration curve. The dissolution profile data of all formulated batches of tablets were fitted to various models such as zero-order (cumulative $\%$ drug release vs time), first-order (log cumulative $\%$ drug remaining vs time), Higuchi [15] (cumulative \% drug release vs square root of time), Korsmeyer et al. [16] (log cumulative \% drug release vs log time) and Hixon and Crowell [17] (cube root of cumulative $\%$ drug remaining vs time) models to ascertain the kinetic modeling of drug release.

\section{Results and Discussion}

\subsection{Characterization techniques.}

For characterizing the synthesized carboxymethylated guar gum, various techniques were employed and are discussed here under.

\subsubsection{FTIR}

The FTIR spectra of native guar gum and carboxymethylated guar gum are shown in Figure 2 and Figure 3. In the FTIR spectra of guar gum, broad band at $3444.89 \mathrm{~cm}^{-1}$ is attributed to $\mathrm{O}-\mathrm{H}$ stretching vibration. A symmetrical stretching vibration due to $-\mathrm{CH}_{2}$ - group was observed at $2925.24 \mathrm{~cm}^{-1}$. Band at $1639.18 \mathrm{~cm}^{-1}$ was assigned to $\mathrm{O}-\mathrm{H}$ bonds of absorbed water molecules and the bands between $800-1000 \mathrm{~cm}^{-1}$ were due to skeletal stretching vibrations of guar gum. 


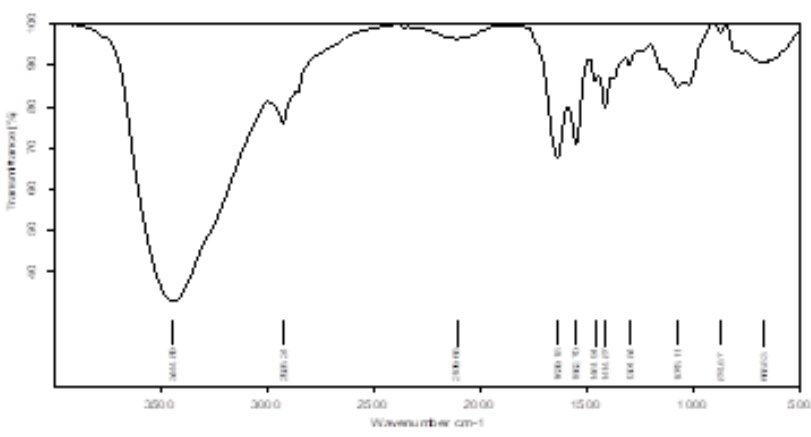

Figure 2. FTIR spectra of pure guar gum.

The carboxymethylated guar gum shows broad band of around $3438.52 \mathrm{~cm}^{-1}$ is attributed to $\mathrm{O}-\mathrm{H}$ stretching vibration. The reduced intensity of absorption band at 3438.52 $\mathrm{cm}^{-1}$ indicates the carboxymethylation of $\mathrm{O}-\mathrm{H}$ groups of guar gum. Increased intensity and sharpness peaks at $1078.81 \mathrm{~cm}^{-1}(\mathrm{C}-\mathrm{O}$ symmetrical and asymmetrical vibrations $)$ and 1374.30 $\mathrm{cm}^{-1}$ (COO- symmetric stretching vibrations) indicate that the hydroxyl groups of guar gum molecules were carboxymethylated.

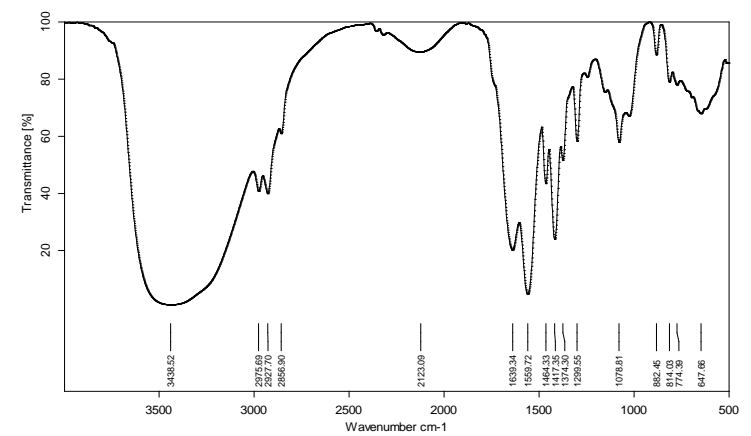

Figure 3. FTIR spectra of carboxymethylated guar gum

\subsubsection{SEM}

Scanning electron microscopy was performed for investigating the surface morphology of the pure guar gum and carboxymethylated guar gum (Figure 4,5). Pure gum exhibited irregular but smooth surface with round edges. However, carboxymethylated gum depicts surface roughness with relatively irregular edges. The carboxymethylation process could be accounted for these structural changes.

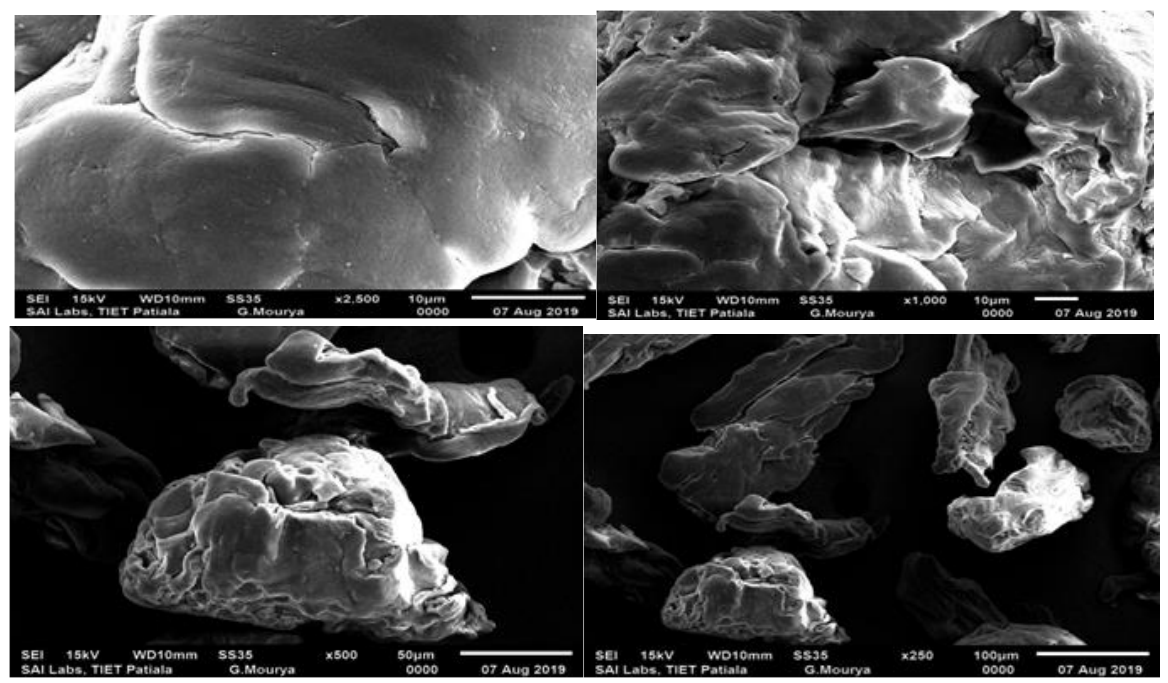

Figure 4. SEM micrographs of pure guar gum at different magnifications. 


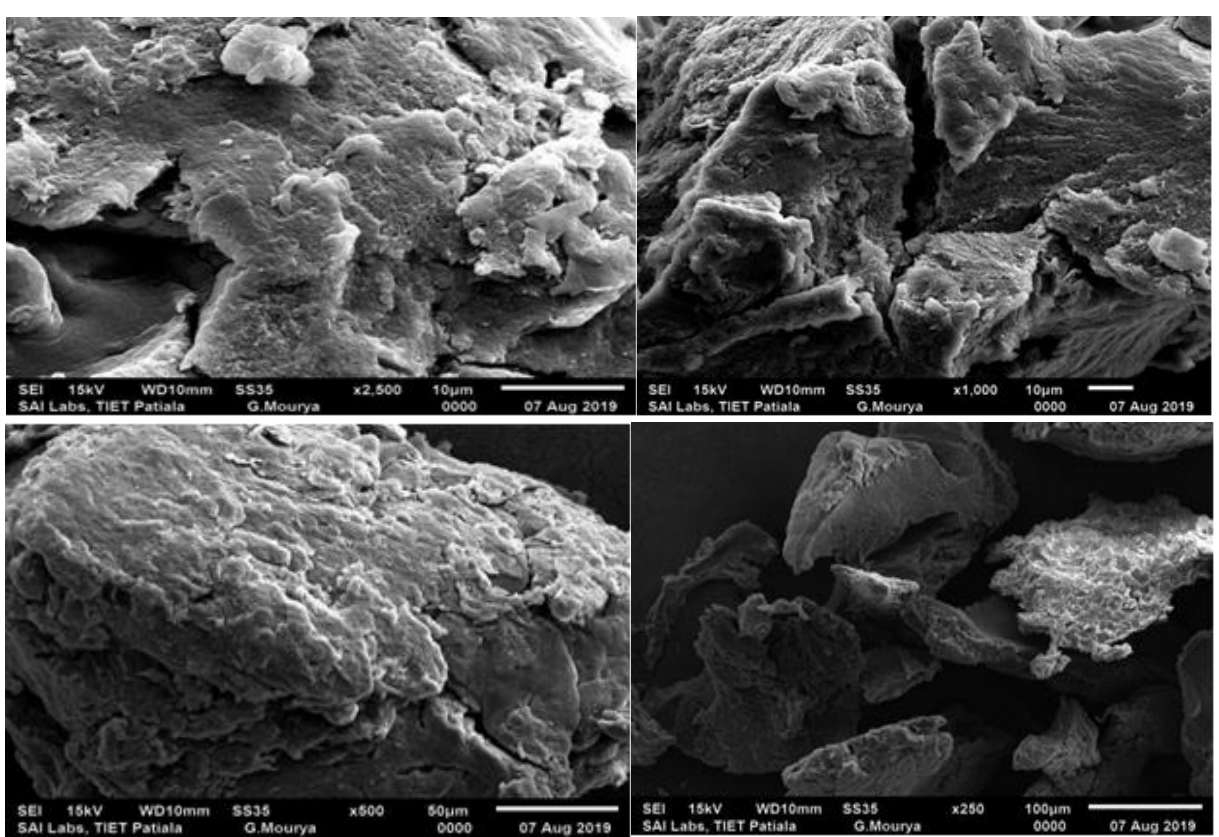

Figure 5. SEM micrographs of carboxymethylated guar gum at different magnifications.

\subsubsection{XRD.}

The X-ray diffractogram of pure guar gum and carboxymethylated guar gum is shown in Figure 6 and Figure 7 Details of the different peaks as shown in the table. The pure guar gum exhibited low crystalline behavior similar to other galactomannan reported in the literature. After carboxymethylation of the guar gum reduction in the crystalline behavior was reported (Table 3 and 4). This could be due to the replacement of the hydroxyl group of the guar gum by the carboxymethyl group [11].

Table 3. X-ray diffractogram of Pure Guar gum.

\begin{tabular}{|c|c|c|c|}
\hline Pos. $\left[{ }^{\circ} 2 \mathrm{Th}.\right]$ & d-spacing $[\AA]$ & Rel. Int. [\%] & Area [cts $\left.{ }^{* \circ} 2 \mathrm{Th}.\right]$ \\
\hline 3.62 & 24.37 & 2.38 & 22.71 \\
\hline 17.64 & 5.02 & 56.77 & 1433.95 \\
\hline 20.38 & 4.35 & 100.00 & 3021.91 \\
\hline 26.53 & 3.35 & 1.31 & 0.00 \\
\hline
\end{tabular}

Table 4. X-ray diffractogram of Carboxymethylated Guar gum.

\begin{tabular}{|c|c|c|c|}
\hline Pos. $\left[{ }^{\circ}\right.$ 2Th. $]$ & d-spacing $[\AA]$ & Rel. Int. [\%] & Area [cts ${ }^{* \circ} 2$ Th.] \\
\hline 3.64 & 24.23 & 0.01 & 0.00 \\
\hline 20.15 & 4.40 & 85.66 & 246.71 \\
\hline 20.47 & 4.33 & 100.00 & 4102.38 \\
\hline 26.71 & 3.33 & 0.77 & 107.81 \\
\hline
\end{tabular}

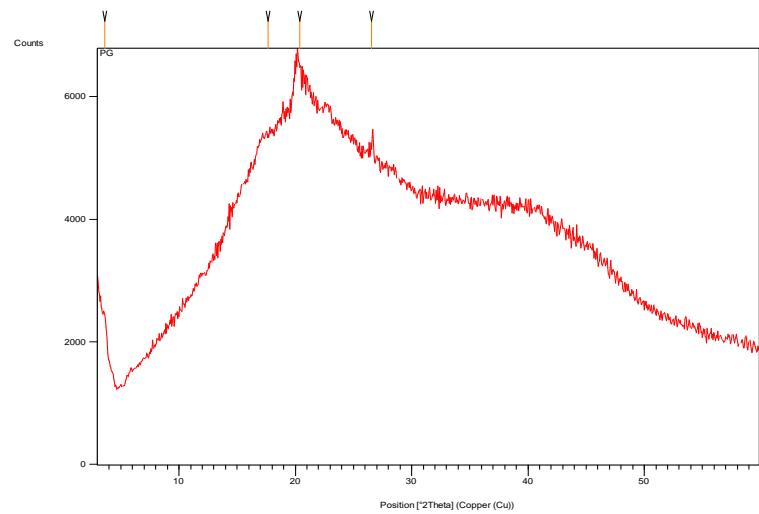

Figure 6. X-ray diffractogram of pure guar gum. 


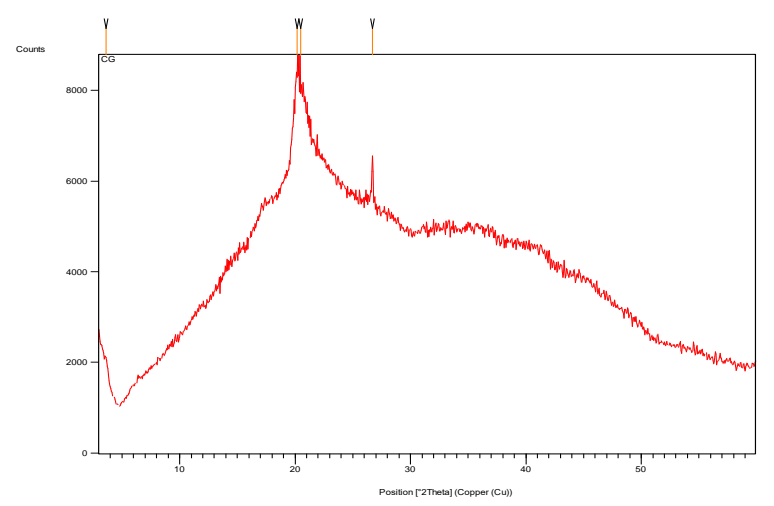

Figure 7. X-ray diffractogram of carboxymethylated guar gum.

\subsubsection{DSC.}

Differential scanning calorimetry (DSC) thermograms of pure guar gum and carboxymethylated guar gum are shown in Figure 8 and 9 respectively. Pure guar gum shows endothermic peak at $68.96^{\circ} \mathrm{C}$ with $-29.76 \mathrm{~mJ}$ enthalpy. However, carboxymethylated guar gum shows endothermic peaks at $62.96{ }^{\circ} \mathrm{C}$ and $267.09{ }^{\circ} \mathrm{C}$ with $-12.25 \mathrm{~mJ}$ and $0.020 \mathrm{~mJ}$ enthalpies respectively. The endothermic peak at $267.09^{\circ} \mathrm{C}$ in the modified gum could be attributed to the thermal degradation of chemical compounds inserted on the gum structure after carboxymethylation.

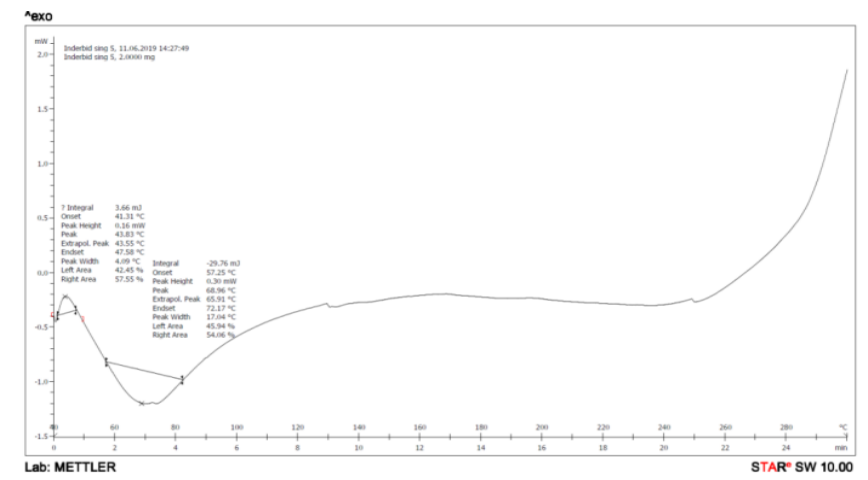

Figure 8. DSC thermogram of purified Guar gum.

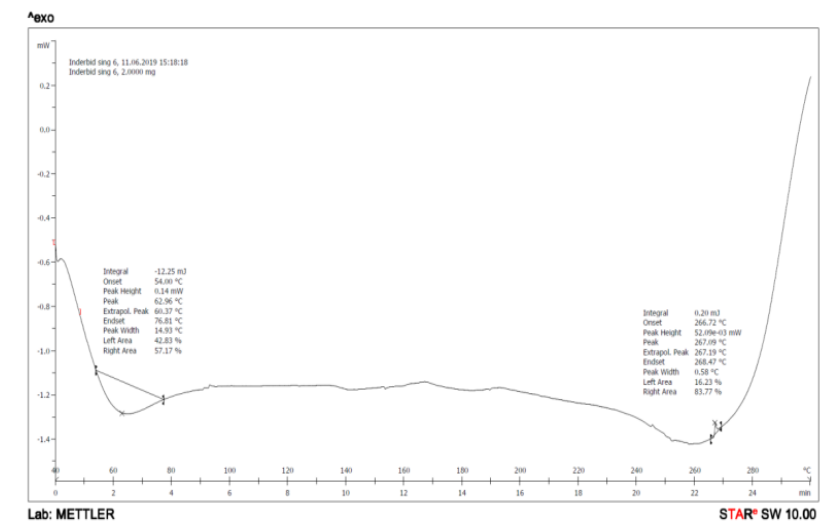

Figure 9. DSC thermogram of carboxymethylated guar gum.

\subsection{Evaluation of core tablets.}

The results of various evaluation parameters for core tablets are depicted in Table 5. The weight of the inner core tablets of cinnarizine was $80 \pm 5 \mathrm{mg}$. Hardness and friability of 
tablets were $3.0 \pm 0.50 \mathrm{~kg} / \mathrm{cm}^{2}$ and $0.80 \pm 0.17 \%$ respectively. The thickness of the core tablets was $1.75 \pm 0.10 \mathrm{~mm}$.

Table 5. Evaluation parameters of inner core tablets

\begin{tabular}{c|c|c} 
S.No. & Parameters & Results \\
\hline 1 & Weight Variation & $80 \pm 5 \mathrm{mg}$ \\
\hline 2 & Hardness & $3.0 \pm 0.50 \mathrm{~kg} / \mathrm{cm}^{2}$ \\
\hline 3 & Friability & $0.80 \pm 0.17 \%$ \\
\hline 4 & Thickness & $1.75 \pm 0.10 \mathrm{~mm}$
\end{tabular}

\subsection{Evaluation of compression coated tablets.}

The results of compression coated tablets prepared using pure gum and carboxymethylated gum in different proportions for coating the previously prepared inner core tablets of cinnarizine are depicted in Table 6. The mucoadhesive detachment force of F1GG to F4GG was found to be ranging between $4.32 \pm 0.89$ and $8.99 \pm 0.75 \mathrm{~g}$. For F1CGG to F4CGG the value of $F_{\max }$ was found to be $10.86 \pm 1.23$ and $18.53 \pm 2.08 \mathrm{~g}$. A significant increase in mucoadhesive property of carboxymethyl guar gum was noticed when compared with pure guar gum. Moreover, mucoadhesive strength was found to increase with increasing in concentration of carboxymethyl guar gum as a coating material in the compression coated mucoadhesive tablets of cinnarizine.

Table 6. Evaluation Parameters of Pure Guar gum and carboxymethylated guar gum used compressed coated tablet.

\begin{tabular}{c|c|c|c|c|c|c|c|c|c|c|c} 
Batch No. & \multicolumn{2}{|c|}{ Zero order } & \multicolumn{2}{c|}{ First Order } & \multicolumn{2}{c|}{ Higuchi } & \multicolumn{3}{c}{ Korsmeyer-Peppas } & \multicolumn{2}{c}{ Hixon-Crowell } \\
\hline & $\mathrm{r}^{2}$ & $\mathrm{~K}_{0}$ & $\mathrm{r}^{2}$ & $\mathrm{~K}_{1}$ & $\mathrm{r}^{2}$ & $\mathrm{~K}_{\mathrm{H}}$ & $\mathrm{r}^{2}$ & $\mathrm{n}$ & $\mathrm{K}_{\mathrm{KP}}$ & $\mathrm{r}^{2}$ & $\mathrm{~K}_{\mathrm{HC}}$ \\
\hline F1GG & 0.6716 & 25.5517 & 0.9221 & -0.8088 & 0.9738 & 9.197 & 0.9684 & 0.443 & 6.4395 & 0.8485 & 0.1742 \\
\hline F2GG & 0.6700 & 18.5263 & 0.9572 & -0.6396 & 0.9661 & 9.2616 & 0.9941 & 0.476 & 6.2728 & 0.8828 & 0.1331 \\
\hline F3GG & 0.6679 & 12.4491 & 0.9682 & -0.5173 & 0.9535 & 9.3337 & 0.9994 & 0.4438 & 6.0458 & 0.9138 & 0.0988 \\
\hline F4GG & 0.7278 & 9.4375 & 0.9814 & -0.3504 & 0.9315 & 9.4787 & 0.9922 & 0.493 & 5.6119 & 0.928 & 0.0711 \\
\hline F1CGG & 0.5038 & 6.5153 & 0.8480 & -0.3941 & 0.9552 & 9.8677 & 0.9300 & 0.588 & 6.267 & 0.7561 & 0.0644 \\
\hline F2CGG & 0.6627 & 7.1735 & 0.9601 & -0.3151 & 0.9356 & 9.7096 & 0.9855 & 0.460 & 5.7304 & 0.8967 & 0.0596 \\
\hline F3CGG & 0.7316 & 7.2908 & 0.9730 & -0.2776 & 0.9266 & 9.5731 & 0.9977 & 0.515 & 5.4627 & 0.9346 & 0.0557 \\
\hline F4CGG & 0.8290 & 7.7194 & 0.9233 & -0.2629 & 0.9113 & 9.6104 & 0.9926 & 0.534 & 4.9473 & 0.9469 & 0.0547
\end{tabular}

\subsection{In vitro drug release.}

In vitro drug release profiles of core tablet and different batches of compression coated mucoadhesive tablets prepared with guar gum (F1GG to F4GG) and carboxymethyl guar gum (F1CGG to F4CGG) are shown in Figure 10 and 11. Carboxymethylated guar gum depicts sustained release behaviour in the compression coated tablets of cinnarizine.

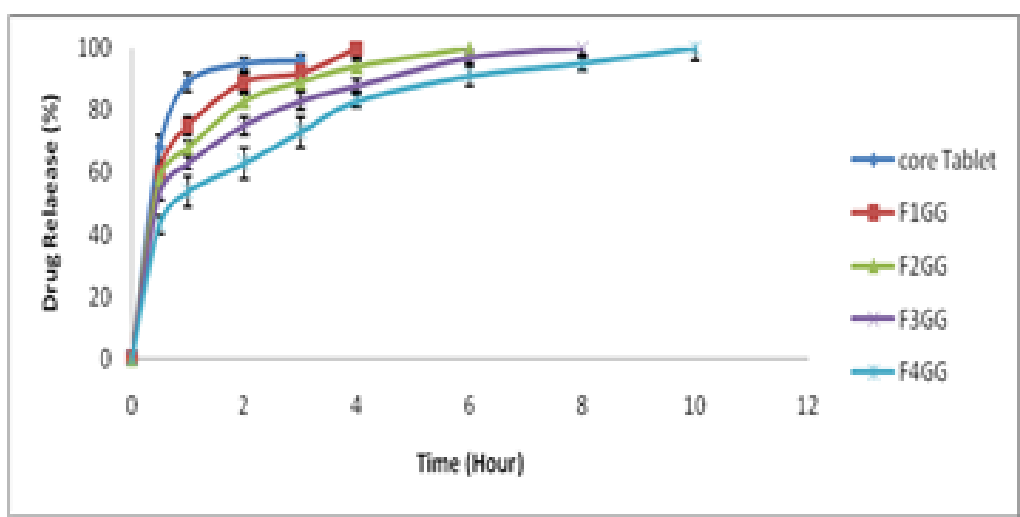

Figure 10. In vitro drug release from core tablet and different batches of compression coated tablets of guar gum. 


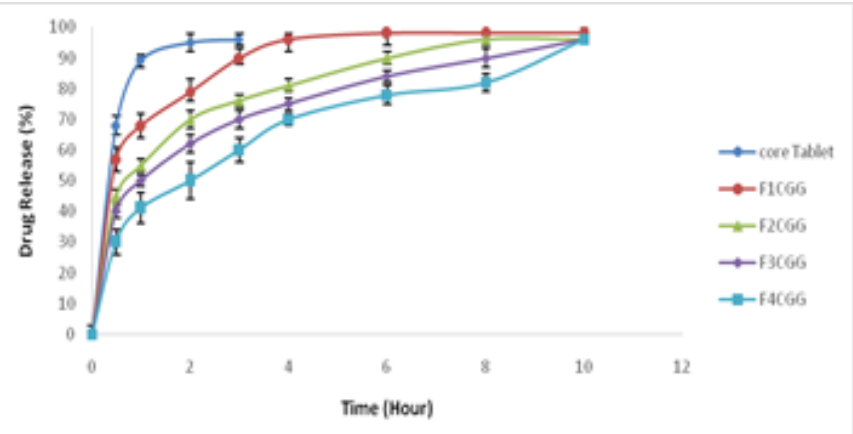

Figure 11. In vitro drug release from core tablet and different batches of compression coated tablets of carboxymethylated guar gum.

Table 7. In vitro drug release (kinetic modeling) data of the formulated batches.

\begin{tabular}{c|c|c|c|c|c|c|c|c|c|c|c} 
Batch No. & \multicolumn{2}{c}{ Zero order } & \multicolumn{2}{c|}{ First Order } & \multicolumn{2}{c|}{ Higuchi } & \multicolumn{3}{|c|}{ Korsmeyer-Peppas } & \multicolumn{2}{c}{ Hixon-Crowell } \\
\hline & $\mathrm{r}^{2}$ & $\mathrm{~K}_{0}$ & $\mathrm{r}^{2}$ & $\mathrm{~K}_{1}$ & $\mathrm{r}^{2}$ & $\mathrm{~K}_{\mathrm{H}}$ & $\mathrm{r}^{2}$ & $\mathrm{n}$ & $\mathrm{K}_{\mathrm{KP}}$ & $\mathrm{r}^{2}$ & $\mathrm{~K}_{\mathrm{HC}}$ \\
\hline F1GG & 0.6716 & 25.5517 & 0.9221 & -0.8088 & 0.9738 & 9.197 & 0.9684 & 0.443 & 6.4395 & 0.8485 & 0.1742 \\
\hline F2GG & 0.6700 & 18.5263 & 0.9572 & -0.6396 & 0.9661 & 9.2616 & 0.9941 & 0.476 & 6.2728 & 0.8828 & 0.1331 \\
\hline F3GG & 0.6679 & 12.4491 & 0.9682 & -0.5173 & 0.9535 & 9.3337 & 0.9994 & 0.4438 & 6.0458 & 0.9138 & 0.0988 \\
\hline F4GG & 0.7278 & 9.4375 & 0.9814 & -0.3504 & 0.9315 & 9.4787 & 0.9922 & 0.493 & 5.6119 & 0.928 & 0.0711 \\
\hline F1CGG & 0.5038 & 6.5153 & 0.8480 & -0.3941 & 0.9552 & 9.8677 & 0.9300 & 0.588 & 6.267 & 0.7561 & 0.0644 \\
\hline F2CGG & 0.6627 & 7.1735 & 0.9601 & -0.3151 & 0.9356 & 9.7096 & 0.9855 & 0.460 & 5.7304 & 0.8967 & 0.0596 \\
\hline F3CGG & 0.7316 & 7.2908 & 0.9730 & -0.2776 & 0.9266 & 9.5731 & 0.9977 & 0.515 & 5.4627 & 0.9346 & 0.0557 \\
\hline F4CGG & 0.8290 & 7.7194 & 0.9233 & -0.2629 & 0.9113 & 9.6104 & 0.9926 & 0.534 & 4.9473 & 0.9469 & 0.0547
\end{tabular}

$\mathrm{k}_{0}$ : Zeroorder release rate constant, $\mathrm{k}_{1}$ : Firstorder release rate constant, $\mathrm{K}_{\mathrm{H}}$ : Higuchi release rate constant, $\mathrm{K}_{\mathrm{KP}}$ :

Korsemeyer-Peppas release rate constant, $\mathrm{K}_{\mathrm{HC}}$ : Hixson-Crowell release rate constant, $\mathrm{r}^{2}$ : Regression line value

The in vitro release data was fitted to different kinetic models such as zero-order, firstorder, Higuchi, Korsmeyer-Peppas and Hixon-Crowell as shown in Table 7. The value of $n$ (release exponent) $0.45<\mathrm{n}<0.89$ indicates non-Fickian drug release transport. Drug release from the biopolymer coated tablets follows diffusion and erosion of the polymer (anomalous non-Fickian drug release behavior). When the formulation is in contact with the dissolution media, the media penetrates the polymer matrix leading to disentanglement and subsequent dissolution/erosion of polymer chains resulting in the release of the drug molecules from the dosage form. According to another theory, the glass-rubbery transition of the polymer matrix leads to an increase in the mobility of polymeric chains allowing the drug molecules to dissolve and diffuse through the gel layer [18,19].

\section{Conclusions}

Carboxymethylation of guar gum was performed by simple and efficient chemical method. FTIR, DSC, XRD and SEM techniques were employed for the characterization of the modified gum. Compression coating technique was used for coating the core tablets of cinnarizine for developing sustained release mucoadhesive tablets. Compression coating is an effective solvent free technique for coating the core tablets. Carboxymethylation is a simple and economical method for modifying biopolymers. Carboxymethylated biopolymers can be used for developing different mucoadhesive drug delivery systems for targeting ocular, pulmonary, buccal, rectal, vaginal and gastrointestinal regions. Regulatory and toxicological issues of carboxymethylated biopolymer must be adequately handled before exploiting them for commercial use.

\section{Funding}

This research received no external funding. 


\section{Acknowledgments}

\section{The authors gratefully acknowledge Chitkara College of Pharmacy, Chitkara University,}

Punjab, India for support and institutional facilities.

\section{Conflicts of Interest}

The authors declare no conflict of interest.

\section{References}

1. Andrews, G.P.; Laverty, T.P.; Jones, D.S. Mucoadhesive polymeric platforms for controlled drug delivery. European Journal of Pharmaceutics and Biopharmaceutics 2009, 71, 505-518, https://doi.org/10.1016/j.ejpb.2008.09.028.

2. Singh, I.; Rana, V. Enhancement of mucoadhesive property of polymers for drug delivery applications: A critical review. Reviews on Adhesion and Adhesives 2013, 1, 271290,https://doi.org/10.7569/RAA.2013.097307.

3. Sethi, S.; Mangla, B.; Kamboj, S.; Rana, V. A QbD approach for the fabrication of immediate and prolong buoyant cinnarizine tablet using polyacrylamide-g-corn fibre gum. International Journal of Biological Macromolecules 2018, 117, 350-361, https://doi.org/10.1016/j.ijbiomac.2018.05.178.

4. Singh, I.; Rana, V. Iron oxide induced enhancement of mucoadhesive potential of Eudragit RLPO: formulation, evaluation and optimization of mucoadhesive drug delivery system. Expert Opinion on Drug Delivery 2013, 10, 1179-1191, https://doi.org/10.1517/17425247.2013.790361.

5. George, A.; Shah, P.A.; Shrivastav, P.S. Guar gum: Versatile natural polymer for drug delivery applications. European Polymer Journal 2019, 112, 722-735, https://doi.org/10.1016/j.eurpolymj.2018.10.042.

6. Sharma, G.; Sharma, S.; Kumar, A.; Al-Muhtaseb, A.H.; Naushad, m.; Ghfar, A.A.; Mola, G.T.; Stadler, F.J. Guar gum and its composites as potential materials for diverse applications: A review. Carbohydrate Polymers 2018, 199, 534-545, https://doi.org/10.1016/j.carbpol.2018.07.053.

7. Dodi, G.; Hritcu, D.; Popa, M.I. Carboxymethylation of guar gum: Synthesis and characterization. Cellulose Chemistry and Technology 2011, 45, 171-176.

8. Singh, R.; Maity, S.; Sa, B. Effect of ionic crosslink on the release of metronidazole from partially carboxymethylated guar gum tablet. Carbohydrate Polymers 2014, 106, 414-421, https://doi.org/10.1016/j.carbpol.2014.01.033

9. Sa, Biswanath.; Mukherjee, S.; Roy, S.K. Effect of polymer concentration and solution pH on viscosity affecting integrity of a polysaccharide coat of compression coated tablets. International Journal of Biological Macromolecules 2019, 125, 922-930, https://doi.org/10.1016/j.ijbiomac.2018.12.101.

10. Gong, L.; Sun, Y.; Yu, M.; Gao, Y.; Zou, M.; Cheng, G. Development and evaluation of compression coating gastro-floating tablet of alfuzosin hydrochloride for zero-order controlled release. AAPS PharmSciTech 2018, 19, 3277-3286 https://doi.org/10.1208/s12249-018-1168-z.

11. Gong, H.; Liu, M.; Chen, J.; Han, F.; Gao, C.; Zhang, B. Synthesis and characterization of carboxymethyl guar gum and rheological properties of its solutions. Carbohydrate Polymers 2012, 88, 1015-1022, https://doi.org/10.1016/j.carbpol.2012.01.057.

12. Raza, A.; Shen, N.; Li, J.; Chen, Y.; Wang, J.Y. Formulation of zein based compression coated floating tablets for enhanced gastric retention and tunable drug release. European Journal of Pharmaceutical Sciences 2019, 132, 163-173, https://doi.org/10.1016/j.ejps.2019.01.025.

13. Malik, D.; Singh, I. Formulation and evaluation of press coated tablets of esomeprazole for colonic delivery. Asian Journal of Pharmaceutics 2012, 6, 252-258.

14. Koradia, H.; Chaudhari, K. Formulation of unidirectional buccal tablet of mirtazapine: An in vitro and ex vivo evaluation. Journal of Drug Delivery Science and Technology 2018, 43, 233-242, https://doi.org/10.1016/j.jddst.2017.10.012.

15. Higuchi, T. Mechanism of sustained-action medication. Theoretical analysis of rate of release of solid drugs dispersed in solid matrices. Journal of Pharmacentical Sciences 1963, 52, 1145-1149, https://doi.org/10.1002/jps.2600521210.

16. Korsmeyer, R.W.; Gurny, R.; Doelker, E.; Buri, P.; Peppas, R.A. Mechanism of solute release from porous hydrophilic polymers. International Journal of Pharmaceutics 1983, 15, 25-35, https://doi.org/10.1016/0378-5173(83)90064-9.

17. Hixson, A.W.; Crowell, J.H. Dependence of reaction velocity upon surface and agitation (I) theoretical consideration. Ind Eng Chem 1931, 23, 923-931, https://doi.org/10.1021/ie50260a018. 
18. Barmpalexis, P.; Kachrimanis, K.; Malamataris. S. Statistical moments in modelling of swelling, erosion and drug release of hydrophilic matrix-tablets. International Journal of Pharmaceutics 2018, 540, 1-10, https://doi.org/10.1016/j.ijpharm.2018.01.052.

19. Hattori, Y.; Takaku, T.; Otsuka, M. Mechanochemical effect on swelling and drug release of natural polymer matrix tablets by X-ray computed tomography. International Journal of Pharmaceutics 2018, 539, 31-38, https://doi.org/10.1016/j.ijpharm.2018.01.020. 